Ann. Génét. Sél. anim., I974, 6 (4), 497-500.

NOTE

\title{
ABSENCE D'ANTICORPS SPÉCIFIQUES DES GROUPES SANGUINS CHEZ DES BOVINS IMMUNISÉS A L'AIDE DE SPERMATOZOÏDES DE TAUREAU
}

\author{
C. PRAKASH ( $\left.{ }^{1}\right)$ \\ avec la collaboration technique de Dominique SErTz \\ Laboratoire de Génétique biochimique, \\ Centre national de Recherches zootechniques, I. N. R. A., \\ 78350 Jouy en Josas

\section{RÉSUMÉ}

L'immunisation de 4 bovins dans des conditions rigoureusement contrôlées, à l'aide de doses relativement faibles de spermatozoïdes de taureau dépourvus de cellules ou débris cellulaires diploïdes, n'a pas fait apparaître d'anticorps spécifiques des antigènes des groupes sanguins.

\section{INTRODUCTION}

Le présent travail a eu pour but de rechercher si l'iso-immunisation à l'aide de spermatozoïdes bovins dépourvus de cellules diploïdes, de débris cellulaires et de plasma séminal, pouvait provoquer l'apparition d'anticorps spécifiques des antigènes de groupe sanguin. Il s'agissait notamment de vérifier si les réactions immunologiques observables in vitro entre les spermatozoïdes et certains alloantigènes traduisent l'existence, sur la membrane des spermatozoïdes, d'antigènes véritablement assimilables à des facteurs érythrocytaires. En outre, les antisérums attendus auraient $\mathrm{pu}$, de manière générale, servir à identifier des antigènes propres aux spermatozoïdes, ainsi que leur polymorphisme.

\section{MÉTHODES E'T RÉSULTATS}

1. - Choix des donneurs et des receveurs

Les 4 taureaux donneurs de sperme sont des sujets de race Normande entretenus au Centre d'Insémination artificielle de Mayenne. Les 4 receveurs ont été choisis parmi 15 génisses vierges

(1) Adresse actuelle : Division of immunobiology, Karolinska Institute Stockholm (Sweden). 
disponibles pour cette expérimentation dans le troupeau de la Station de Génétique quantitative et appliquée, La Minière, Versailles. Des échantillons de sérum de ces receveurs potentiels ont été examinés, à la dilution $\mathbf{I} / 5$ et à l'aide d'un sérum fluorescent anti- $\gamma$-globuline bovine, dilué $1 / 30$ et préparé par nous-même, pour dépister d'éventuels anticorps anti-spermatozoïdes ; ces essais ont donné des résultats négatifs. Par contre, le sérum de l'un de ces bovins possédait une faible activité antilymphocytaire, décelable par un test de microcytotoxicité; ce bovin a donc été écarté de l'expérience.

L'appariement des donneurs et des receveurs a été fait sur la base des antigènes érythrocytaires, de manière à rendre maximales les chances d'obtenir une stimulation de la synthèse d'anticorps spécifiques des antigènes de groupes sanguins. Le tableau $\mathbf{r}$ donne la liste des facteurs érythrocytaires présents chez les donneurs et absents chez les receveurs correspondants, liste qui équivaut à celle des anticorps attendus dans cette optique. Les receveurs étaient âgés d'environ un an au moment de l'immunisation première. Leur race figure dans le tableau r. Les taureaux choisis comme donneurs avaient 2 ans $1 / 2$ à 3 ans $I / 2$, et étaient utilisés couramment pour l'insémination artificielle.

\section{2. - Protocole d'immunisation}

Pour éviter la contamination bactérienne plus élevée des premiers éjaculats, le sperme utilisé ne provient que de deuxièmes éjaculats. Aussitôt après la collecte est effectué un contrôle de motilité des spermatozoïdes, puis le sperme est lentement amené à la température ambiante et transporté au laboratoire. Environ ro heures après la collecte, le sperme est dilué et les spermatozoïdes séparés des autres cellules et des débris cellulaires par centrifugation dans un gradient de densité (Prakash, I974 a). Les tampons utilisés sont dépourvus de sérum-albumine bovire pour éviter de provoquer une immunisation vis-à-vis de celle-ci. Les spermatozoïdes sont lavés trois fois à l'eau physiologique (9,16 $\mathrm{g}$ de $\mathrm{NaCl}$ par litre d'eau bi-distillée) avec centrifugation à I $500 \mathrm{~g}$ pendant ro minutes, puis mis en suspension dans l'eau physiologique et congelés par fractions de $3 \mathrm{ml}$ à $20^{\circ} \mathrm{C}$ jusqu'au moment de leur utilisation. Cette préparation demande environ 3 heures, et peut donc être achevée 13 heures après la collecte.

Le protocole d'immunisation proprement dit comporte, pour l'immunisation première, deux injections intramusculaires de $3 \mathrm{ml}$ chacune pratiquées à une semaine d'intervalle; toutefois chez le bovin 85 , l'intervalle a été de 12 jours. La quantité de spermatozoïdes injectés figure dans

\section{TABLEAU I}

Détails de protocole d'immunisation de 4 bovins par des spermatozoïdes de taureaux

\begin{tabular}{|c|c|c|c|c|}
\hline \multirow{2}{*}{$\begin{array}{l}\text { Numéro et race } \\
\text { du donneur } \\
\text { de sperme }\end{array}$} & \multirow{2}{*}{$\begin{array}{l}\text { Numéro et race } \\
\text { du receveur }\end{array}$} & \multicolumn{2}{|c|}{$\begin{array}{c}\text { Nbre de spermatozoïdes } \\
\text { à chaque injection }\end{array}$} & \multirow{2}{*}{$\begin{array}{c}\text { Facteurs antigéniques } \\
\text { érythrocytaires, présents } \\
\text { chez le donneur et absents } \\
\text { chez le receveur }\end{array}$} \\
\hline & & $\begin{array}{l}\text { Immuni- } \\
\text { sation } \\
\text { première }\end{array}$ & $\begin{array}{l}\text { Immuni- } \\
\text { sation } \\
\text { de rappel }\end{array}$ & \\
\hline $\mathrm{D}_{1}$, Normand & $\begin{array}{l}\text { (i7, Charolais } \times \text { Blonde } \\
\text { d'Aquitaine }\end{array}$ & $123 \cdot 10^{6}$ & $687 \cdot 10^{6}$ & $\begin{array}{l}\mathrm{B}, \mathrm{O}_{3}, \mathrm{Y}, \mathrm{A}^{\prime}, \mathrm{E}_{3}^{\prime}, \mathrm{G}^{\prime}, \mathrm{P}^{\prime}, \mathrm{Q}^{\prime}, \mathrm{C}_{1}, \mathrm{C}_{2}, \\
\quad \mathrm{E}, \mathrm{R}_{2}, \mathrm{X}_{1}, \mathrm{X}_{2}, \mathrm{~F}_{15}, \mathrm{~V}, \mathrm{~J}\end{array}$ \\
\hline $\mathrm{D}_{2}$ & 85 , Charolais $\times$ Gasconne & $690 \cdot 10^{6}$ & $187 \cdot 10^{6}$ & $C_{1}, C_{2}, X_{2}, V$ \\
\hline $\mathrm{D}_{3}$ & $\begin{array}{l}\text { 93, Charolais } \times \text { Blonde } \\
\text { d'Aquitaine }\end{array}$ & $798 \cdot 10^{6}$ & $137 \cdot 10^{6}$ & $\begin{array}{l}B, G_{1}, G_{2}, I_{1}, I_{2}, Q, A^{\prime}, K^{\prime}, Q^{\prime}, F_{3}, \\
\quad F_{4}, X_{2}\end{array}$ \\
\hline $\mathrm{D}_{4}$ & 65, Blonde d'Aquitaine & $615 \cdot 10^{8}$ & $275 \cdot 10^{6}$ & $\begin{array}{c}\mathrm{G}_{1}, \mathrm{G}_{2}, \mathrm{I}_{1}, \mathrm{I}_{1}, \mathrm{O}_{3}, \mathrm{Y}, \mathrm{A}^{\prime}, \mathrm{E}_{2}^{\prime}, \mathrm{E}_{3}^{\prime}, \mathrm{K}^{\prime} \\
\quad \mathrm{I}^{\prime}, \mathrm{P}^{\prime}, \mathrm{Q}^{\prime}, \mathrm{F}_{4}, \mathrm{C}_{1}, \mathrm{C}_{2}, \mathrm{E}, \mathrm{R}_{2}, \mathrm{~V}, \mathrm{Z}\end{array}$ \\
\hline
\end{tabular}


le tableau I. Chaque dose d'immunisation contenant par ailleurs 20 ooo UI de pénicilline et ıoo mg de streptomycine. Nous n'avons jamais observé, chez aucun des receveurs, de réactions à l'immunisation.

Des prises de sang ont été effectuées avant la première injection et quatre jours après la seconde. Le sérum, séparé du culot et inactivé à $5^{\circ} \mathrm{C}$ pendant $3^{\circ}$ minutes, a été stocké à l'état congelé entre $-20^{\circ} \mathrm{C}$ et $-70^{\circ} \mathrm{C}$ jusqu'à son emploi.

L'immunisation de rappel a été effectuée 7 mois environ après l'immunisation première. Les deux injections ont été faites à 4 ou 5 jours d'intervalle, avec les doses de spermatozoïdes figurant au tableau I. Les prises de sang ont été faites 3 jours après la seconde injection.

\section{3. - Etude sérologique}

Les sérums ainsi obtenus ont été examinés suivant les techniques sérologiques habituellement utilisées dans ce laboratoire. Après l'immunisation première nous n'avons pu déceler aucune réaction hémolytique vis-à-vis des globules rouges des donneurs.

Les quatre sérums prélevés après l'immunisation de rappel ont été examinés, non dilués et dilués $\mathrm{I} / 4$, à l'aide de 42 suspensions érythrocytaires individuelles par les techniques classiques utilisées dans les études de groupes sanguins. A l'exception d'un anti-J naturel présent chez le bovin 85 , aucun anticorps n'a pu être décelé.

Ces sérums n'ont d'autre part donné aucune réaction avec I 80 échantillons de sang, de génotype très varié, analysés par le laboratoire dans le cadre de ses activités.

\section{DISCUSSION}

Nous avons passé en revue récemment l'ensemble des publications qui rapportent des recherches visant à déceler la présence, sur les spermatozoïdes, d'antigènes de groupe sanguin ou d'histocompatibilité (Prakash, 1973). Docton et al. (1962) sont parvenus à produire des anticorps spécifiques des groupes sanguins en immunisant des lapins avec des spermatozoïdes bovins. Papivanov et Vulchanov (1962) ont de même décrit l'obtention d'anti-A par immunisation des lapins à l'aide de spermatozoïdes humains provenant de donneurs de groupe A. Par contre Schmid et al., (1964) ont échoué dans leur tentative d'immunisation de bovins par des spermatozoïdes de la même espèce pour en obtenir des réactifs de groupe sanguin.

On peut supposer que la densité relativement faible de sites antigéniques à la surface des spermatozoïdes (Prakash, r974 b) est responsable de l'échec de notre propre tentative d'immunisation, qui a d'ailleurs comporté un nombre d'injections plus faible que celui qui est d'usage dans ce laboratoire lors des iso-immunisations à l'aide d'hématies bovines.

Reçu pour publication en décembre 1974.

\section{REMERCIEMEN'TS}

Je remercie M. F. Grosclaude de l'aide apportée dans la réalisation de ce travail et M. F. Lamétrie, du Centre d'Insémination de Mayenne, pour les dons de sperme bovin. 


\section{SUMMARY}

\section{ABSENCE OF THE, SPECIFIC BLOOD GROUP ANTIBODY PRODUCTION IN CATTLE BY ISOIMMUNIZATION WITH BULL SPERMATOZOA}

The isoimmunization of four virgin heifers under rigorously controlled conditions by the bull spermatozoal suspension completely free from cells and cellular debris contaminations of diploid origin did not result in the production of specific antibodies for the antigens of blood groups.

\section{RÉFÉRENCES BIBLIOGRAPHIQUES}

Docton F. L., Ferguson L. C., Lazear E. J., Ely F., I952. The antigenicity of bovine spermatozoa. J. Dairy Sci., 35, 7o6-709.

Papivanov R., Vulchanov V. H., I962. Segregation of man's AB group spermatozoa in $A$ and B- spermatozoa through agglunitation with immune anti-A rabbit serum. C. R. Acad. Sci. Bulg., 15, $669-672$.

Prakash C., I973. Les alloantigènes sur les spermatozoïdes de mammifères. Déterminisme de ces antigènes par le génome haploïde des spermatozoïdes. Ann. Génét. Sél. anim., 5, 507-5I8.

Prakash C., $1974 a$. Séparation des spermatozoïdes mobiles des autres cellules et des débris cellulaires présents dans le sperme bovin. Ann. Biol. Anim. Bioch. Biophys., 14, 363-369.

PrAkash C., I974 b. Mise en évidence, sur les spermatozoïdes bovins de quelques antigènes appartenant au système de groupes sanguins S. Ann. Génét. Sél. anim., 6, I-I6.

Schmid D. O., Conneally P. M., Stone W. H., i964. Blood Group antigens on bull spermatozoa. J. Animal Sci., 23, I198-II99 (Abst).

Vulchanov V. H., Papivanov R., 1972. Immunological data suggesting post segregational gene action in human spermatozoa, in BeAtTy R. A., GLUECKs-Waelsch S., The Genetics of the spermatozoan. Proc. int. Symp., Univ. Edimburgh, I77-I9o. 